\title{
Importance of "acknowledging and reducing treatment uncertainty" in appraisal and revalidation
}

\author{
lan Roberts professor of epidemiology and public health ${ }^{1}$, Brigitte Chaudhry founder ${ }^{2}$, lain Chalmers \\ coordinator $^{3}$
}

'London School of Hygiene and Tropical Medicine, London WC1E 7HT, UK; ${ }^{2}$ RoadPeace, London, UK; ${ }^{3}$ James Lind Initiative, Oxford, UK

Last year we criticised the General Medical Council (GMC) for omitting from its 2013 edition of Good Medical Practice its previous view that doctors "must work with colleagues and patients ... to help resolve uncertainties about the effects of treatments." ${ }^{1-3}$ We welcome the council's recently published statement that it regards "Medical research [as] vital to improving care for patients both now and in the future," its call on doctors to consider whether they could do more to support medical research. ${ }^{3}$ In particular, we are pleased to see that the GMC is now urging doctors to raise patients' awareness of the importance of research; to look for opportunities for themselves and patients to become involved in research studies, and to tell patients about them so they can decide if they would like to take part; and, lastly, to support patients who choose to take part in studies.

We share the council's view that such actions will reduce risks for patients. Indeed, we believe that acknowledging uncertainties about the effects of treatments and seeking to reduce them by increasing the number of patients enrolled in well designed clinical trials is a more patient centred form of "reflective practice" than the reflection currently being endorsed by the GMC. We urge the GMC to take the next (small) step and give "acknowledging and reducing treatment uncertainty" the same degree of emphasis in appraisal and revalidation as is currently devoted to reflective practice.

Competing interests: None declared.

1 Roberts I, Chaudhry B, Chalmers I. New GMC guidance takes a major, ethically flawed, backward step. BMJ 2013;346:f3879.

2 General Medical Council. Good medical practice. 2013. www.gmc-uk.org/guidance/good medical_practice.asp.

3 General Medical Council. Good medical practice. 2006. www.gmc-uk.org/Good_Medical_ Practice__Archived.pdf_51772200.pdf.

4 General Medical Council. Could you do more to support medical research? GMC News 2014. http://gmc-news.org/OUY-2CC12-8BG11T-10IKBD-1/c.aspx. 